\title{
Silencing of SNX1 by siRNA stimulates the ligand-induced endocytosis of EGFR and increases EGFR phosphorylation in gefitinib-resistant human lung cancer cell lines
}

\author{
YUKIO NISHIMURA ${ }^{1}$, SOICHI TAKIGUCHI ${ }^{2}$, KIYOKO YOSHIOKA ${ }^{3}$, \\ YUSAKU NAKABEPPU ${ }^{4}$ and KAZUYUKI ITOH ${ }^{3}$
}

\begin{abstract}
${ }^{1}$ Division of Pharmaceutical Cell Biology, Graduate School of Pharmaceutical Sciences, Kyushu University, Fukuoka 812-8582; ${ }^{2}$ Institute for Clinical Research, National Kyushu Cancer Center, Fukuoka 811-1395; ${ }^{3}$ Department of Biology, Osaka Medical Center for Cancer and Cardiovascular Diseases, Osaka 537-8511;

${ }^{4}$ Division of Neurofunctional Genomics, Department of Immunobiology and Neuroscience, Medical Institute of Bioregulation, Kyushu University, Fukuoka 812-8582, Japan
\end{abstract}

Received May 8, 2012; Accepted July 6, 2012

DOI: $10.3892 /$ ijo.2012.1578

\begin{abstract}
Gefitinib is known to suppress the activation of EGFR signaling, which is required for cell survival and proliferation in non-small cell lung cancer (NSCLC) cell lines. We previously demonstrated that the gefitinib-sensitive NSCLC cell line PC9 shows efficient ligand-induced endocytosis of phosphorylated EGFR (pEGFR). In contrast, the gefitinib-resistant NSCLC cell lines QG56 and A549 showed internalized pEGFR accumulation in the aggregated early endosomes, and this was associated with SNX1, a protein that interacts with and enhances the degradation of EGFR upon EGF stimulation. In the present study, to investigate the role of SNX1 on EGF-stimulated EGFR/pEGFR endocytosis via the endocytic pathway, we examined the effect of depletion of SNX1 expression by siRNA in human NSCLC cell lines. Using immunofluorescence, we demonstrated that transfection of SNX1 siRNA into gefitinib-resistant NSCLC cells resulted in the disappearance of a large amounts of SNX1 staining. In addition, upon 15 min of EGF stimulation, we observed an efficient EGFR phosphorylation and a rapid endocytic
\end{abstract}

Correspondence to: Dr Yukio Nishimura, Division of Pharmaceutical Cell Biology, Graduate School of Pharmaceutical Sciences, Kyushu University, 3-1-1 Maidashi, Higashi-ku, Fukuoka 812-8582, Japan

E-mail: ynkio443@gmail.com

Abbreviations: EGFR, epidermal growth factor receptor; pEGFR, phosphorylated epidermal growth factor receptor; SNX1, sorting nexin 1; NSCLC, non-small cell lung cancer; LIMPII, lysosomal integral membrane protein II

Key words: sorting nexin 1, phosphorylated EGF receptor, endocytosis, endosomes/lysosomes, gefitinib, non-small cell lung cancer cell lines delivery of pEGFR from early endosomes to late endosomes. Further, western blot analysis revealed that silencing of SNX1 expression by siRNA in the gefitinib-resistant cells leads to an accelerated degradation of EGFR along with a dramatic increase in the amounts of pEGFR after EGF stimulation. Based on these findings, we suggest that SNX1 is involved in the negative regulation of ligand-induced EGFR phosphorylation and mediates EGFR/pEGFR trafficking out of early endosomes for targeting to late endosomes/lysosomes via the early/late endocytic pathway in human lung cancer cells.

\section{Introduction}

The endocytosis of epidermal growth factor receptor (EGFR) serves as a model for studying ligand-induced receptormediated endocytosis. Upon EGF stimulation, the dimerizd EGF-EGFR complexes are internalized and transported via clathrin-coated vesicles to early endosomes. EGFR then recruits and phosphorylates signaling molecules, leading to the activation of the MAPK-signal transduction cascade, an important mechanism for regulating cell growth (1-4). To turn off EGF signaling, the EGF-EGFR complexes are delivered to the lysosomes for degradation by a process known as receptor downregulation. Therefore, endocytosis of EGF-EGFR complexes is closely related to attenuation of intracellular EGFR signaling. Furthermore, EGFR mediates an important role in the pathogenesis of different tumors, and therapies directed at inhibiting EGFR function have potential as anticancer treatments $(5,6)$.

Gefitinib, a selective EGFR tyrosine kinase inhibitor, has been shown to block the signal transduction pathways implicated in the proliferation and survival of cancer cells (7-10). It was reported previously that of the 9 non-small cell lung cancer (NSCLC) cell lines examined, the PC9 cell line was most sensitive to the effect of gefitinib with respect to EGFR phosphorylation and activation of EGFR downstream effectors such as AKT and those in the ERK1/2 pathway, which are required for EGFR-stimulated proliferation (11). In contrast, 
the other NSCLC lines such as QG56 and A549 cells showed greater resistance to gefitinib (11). Consequently, we hypothesize that the mechanism responsible for determining the sensitivity of the EGFR endocytic pathway could be useful in predicting the potential effectiveness of gefitinib in NSCLC patients. We have previously investigated the endocytosis of Texas red-labeled EGF in the absence or presence of gefitinib in three NSCLC cell lines, and then assessed the amounts of internalized Texas red-EGF or phosphorylated EGFR (pEGFR) by using confocal immunofluorescence microscopy (12-14). We showed that an aberration in certain steps of EGF-EGFR/ pEGFR trafficking from the early endosomes to the late endosomes/lysosomes does occur in the gefitinib-resistant human lung cancer cell line QG56 and A549, whereas endocytosis of EGFR/pEGFR is normal in gefitinib-sensitive PC9 cells (12-14). Accordingly, we suggested that impairment of certain steps of EGF-EGFR/pEGFR trafficking from early endosomes to late endosomes/lysosomes might confer gefitinib-resistance in NSCLC cell lines. Furthermore, we made a novel observation that large amounts of sorting nexin 1 (SNX1) are localized in the aggregated vesicular structures of early endosomes where the internalized pEGFR is also accumulated $(13,14)$. Therefore, we postulate that impairment of protein function, such as the SNX1 regulation of EGFR/pEGFR trafficking in the early endocytic pathway, might perturb EGFR/pEGFR endocytosis, which subsequently leads to gefitinib-resistance in NSCLC cell lines.

SNX1 was previously demonstrated to be a protein that interacts with EGFR (15) and is localized to early endosomes through its phospholipid-binding motif termed the phox homology (PX) domain (16). SNX1 is homologous to Vps5p, a yeast protein that is required for endosome-to-Golgi trafficking (17-19). Previous studies also revealed that overexpression of SNX1 causes enhanced EGFR degradation and that deletion mutant of SNX1 blocked EGFR degradation but failed to inhibit receptor endocytosis $(15,20)$. Therefore, it was suggested that SNX1 interacts with EGFR and enhances the degradation of the receptor upon EGF stimulation, thereby implying that SNX1 plays a role in endosome-lysosome trafficking. However, recent evidence has failed to support the intracellular colocalization of SNX1 with EGFR and its direct role in EGFR degradation, raising the possibility that alternative mechanisms are involved in the function of SNX1 $(21,22)$. Consequently, the molecular mechanism underlying EGFR membrane trafficking remains to be elucidated.

In the present study, we analyzed the intracellular regulatory function of SNX1 with regard to EGF-induced endocytosis and downregulation of EGFR/pEGFR using confocal immunofluorescence microscopy, western blot analysis, and RNAi-mediated knockdown approaches in gefitinib-sensitive and gefitinib-resistant NSCLC cell lines. We demonstrated that silencing of endogenous SNX1 by siRNA stimulates efficient endocytosis of ligand-induced EGFR and pEGFR in gefitinib-resistant NSCLC cells. We also found that depletion of SNX1 stimulates the ligand-induced downregulation of EGFR/pEGFR, while increasing of pEGFR protein expression in gefitinib-resistant cells. Therefore, we postulate that SNX1 plays a negative role in the regulation of EGF-dependent downregulation of EGFR and its phosphorylation via the early/late endocytic pathway in human lung cancer cells.

\section{Materials and methods}

Materials. Texas red-labeled human transferrin, Texas redlabeled EGF, and SlowFade anti-fade reagent were purchased from Molecular Probes (Eugene, OR, USA). DAPI, recombinant human EGF was purchased from PeproTech (London, UK). Bafilomycin A1, and cycloheximide (CHX) were obtained from Sigma (St. Louis, MO, USA). Other chemicals were of reagent grade and were obtained from commercial sources.

Cell culture. Cell lines PC9, QG56 and A549 (National Kyushu Cancer Center, Fukuoka, Japan) were cultured in RPMI supplemented with $10 \%$ fetal bovine serum (FBS). Cells were maintained under standard cell culture conditions at $37^{\circ} \mathrm{C}$ and $5 \% \mathrm{CO}_{2}$ in a humid environment.

Small interfering RNA. siRNA targeting SNX1 was purchased from Dharmacon (Boulder, CO, USA). The target sequence of the siRNA was as follows: 5'-AAGAACAAGACCAAGAGC CAC-3'. Scramble sequence was used as a control. The 3 NSCLC cell lines were transfected with Lipofectamine 2000 (Life Technologies, Gaithersburg, MD, USA) in the presence of $40 \mathrm{nM}$ siRNA targeting SNX1 according to the manufacturer's protocol. Knockdown efficiency was determined by qRT-PCR, and confocal immunofluorescence microscopy analysis.

qRT-PCR analysis. The 3 NSCLC cell lines PC9, QG56 or A549 cells transfected with siRNA-control or siRNA-SNX1 were stimulated with EGF $(100 \mathrm{ng} / \mathrm{ml})$ at $37^{\circ} \mathrm{C}$ for 5,15 , or $30 \mathrm{~min}$, and total RNA was extracted from each cell line using an RNeasy RNA isolation kit (Qiagen, Hilden, Germany) according to the manufacturer's instructions. Transcription into cDNA was done in a $20-\mu 1$ volume using ThermoScript RT-PCR System with random hexamer (Invitrogen, Carlsbad, CA, USA) according to the manufacturer's instructions. All PCR reactions were carried out in a final volume of $25 \mu \mathrm{l}$ and were performed in the ABI PRISM 7000 Sequence Detection System (Applied Biosystems, Foster City, CA, USA) according to the manufacturer's protocol. Sequence-specific primers were quoted from an official website 'PrimerBank' (http:// pga.mgh.harvard.edu/primerbank/) for the indicated genes (Table I). The reaction mix consisted of SYBR Premix Ex Taq (2x) (Takara Bio., Shiga, Japan) $12.5 \mu 1$, ROX Reference Dye (x50) (Takara Bio.) $0.5 \mu 1,0.2 \mu \mathrm{M}$ of each specific forward and reverse primer, and $9 \mu \mathrm{l}$ of diluted cDNA (equivalent to 0.03-2.85 ng of total RNA). Amplifications were done under standard conditions $\left(10 \mathrm{sec}\right.$ at $95^{\circ} \mathrm{C}$ followed by 40 cycles of $5 \mathrm{sec}$ at $95^{\circ} \mathrm{C}$ and $31 \mathrm{sec}$ at $60^{\circ} \mathrm{C}$ ). The number of PCR cycles needed to reach the fluorescence threshold was determined in triplicate for each cDNA, averaged, and then normalized to a reference gene ( $\beta$-actin). A standard curve generated with serial 3 -fold dilutions of a representative cDNA. For all assays tested, the PCR reaction was linear over the range studied (20-40 cycles of amplification). All RT-PCR reactions gave a single band when analyzed by gel electrophoresis.

Antibodies. Alexa 488-labeled goat anti-mouse and goat antirabbit secondary antibodies were obtained from Molecular Probes. Normal rabbit IgG and normal mouse monoclonal IgG1 were purchased from Imgenex (San Diego, CA, USA) and 
Table I. Primers for qRT-PCR for human SNX1, EGFR, and $\beta$-actin.

\begin{tabular}{ll}
$\begin{array}{l}\text { PCR primer } \\
\text { name }\end{array}$ & \multicolumn{1}{c}{ Nucleotide sequence } \\
\hline SNX1-forward & 5'-AGCCCCAGCCAACCTATGA-3' \\
SNX1-reverse & 5'-TCAGGATCAGTTATACCGACTGT-3' \\
EGFR-forward & 5'-GCGTTCGGCACGGTGTATAA-3' \\
EGFR-reverse & 5'-GGCTTTCGGAGATGTTGCTTC-3' \\
$\beta$-actin-forward & 5'-CATGTACGTTGCTATCCAGGC-3' \\
$\beta$-actin-reverse & 5'-CTCCTTAATGTCACGCACGAT-3' \\
\hline
\end{tabular}

Angio-proteomie (Boston, MA, USA), respectively. Normal goat serum was purchased from Sigma. Antisera were raised in rabbits (New Zealand white male) against the native form of LIMPII/LGP85 (23) as described previously. Anti-LIMPII IgG was affinity-purified by protein A Sepharose CL-4B (Sigma), followed by immunoaffinity chromatography using antigenconjugated Sepharose 4B. Mouse monoclonal antibody to SNX1 was purchased from BD Biosciences (San Jose, CA, USA). A mouse monoclonal anti-pEGFR was obtained from Cell Signaling Technology (Beverly, MA, USA), BD Biosciences and Dako Cytomation (Denmark).

Immunofluorescence microscopy (general procedures). Immunofluorescence microscopy was described previously (12-14,24-26). Cells were grown for 2 days on glass coverslips in 6-well plates in RPMI with $10 \%$ fetal bovine serum. Cells were fixed with $3.7 \%$ formaldehyde in phosphate-buffered saline (PBS), pH 7.4, permeabilized in PBS containing 0.1\% saponin. After washing with PBS, cells were blocked with PBS-10\% normal goat serum. All subsequent antibody and wash solutions contained $0.1 \%$ saponin. The PC9, QG56 and A549 cells were incubated with specific primary antibodies (rabbit anti-LIMPII IgGs, mouse anti-pEGFR mAb, or mouse anti-SNX1 mAb), for $1 \mathrm{~h}$, followed by washes with PBS containing $0.1 \%$ saponin and incubation for $1 \mathrm{~h}$ with the secondary antibodies at $20 \mu \mathrm{g} / \mathrm{ml}$. Each cell line was stained with DAPI to reveal nuclei. Controls for antibody specificity were non-immune normal mouse IgG1 or nonimmune normal rabbit IgG. To label early endosomes, cells were incubated with RPMI without FBS for $3 \mathrm{~h}$ at $37^{\circ} \mathrm{C}$ followed by $20 \mathrm{~min}$ incubation in culture medium containing Texas red-conjugated transferrin, and then cells were fixed and double-stained for SNX1 with anti-SNX1 monoclonal antibody and LIMPII with anti-LIMPII antibody. Late endosomes/ lysosomes were stained with anti-LIMPII antibody, since the LIMPII protein is distributed within endocytic organelles and is at its highest concentration in the late endosomes/lysosomes, as observed for other lysosomal glycoproteins, namely, lysosomal-associated membrane protein-1 (LAMP-1) and LAMP-2 $(23,27,28)$. The distribution of the labeled proteins was then analyzed by confocal immunofluorescence microscopy of the fixed cells. Slides were mounted with SlowFade anti-fade reagent and observed on a Zeiss LSM 510 META confocal laser scanning microscope (Carl Zeiss, Oberkochen, Germany), equipped with krypton/argon laser sources. For quantification of co-localization between Texas Red-EGF and LIMPII or pEGFR and LIMPII, merged images as yellow color were quantified and presented as the percentage of total amounts of LIMPII-positive vesicles per cell.

Immunofluorescence microscopy (treatment the cells with $E G F)$. In order to clarify EGFR internalization, we followed the uptake of Texas red-conjugated EGF with time in each cell line. To minimize the contribution of recycling and/or lysosomal degradation of the internalized EGFR, we quantified the Texas red-EGF uptake in each cell for time periods of up to $60 \mathrm{~min}$. At 48 h transfection, PC9, QG56 and A549 cells treated with siRNA-control or siRNA-SNX1 were starved for $12 \mathrm{~h}$ with RPMI without $\mathrm{FBS}$ at $37^{\circ} \mathrm{C}$ and the serum-starved cells were then incubated with Texas red-EGF $(100 \mathrm{ng} / \mathrm{ml})$ at $37^{\circ} \mathrm{C}$ for 15,30 , or $60 \mathrm{~min}$, and the distribution of internalized Texas red-EGF and late endosomes/lysosomes stained with anti-LIMPII antibody was then assessed by confocal immunofluorescence microscopy. In some cases, cells were starved for $3 \mathrm{~h}$ with RPMI without FBS at $37^{\circ} \mathrm{C}$ and then the phosphorylation of EGFR was induced with EGF $(100 \mathrm{ng} / \mathrm{ml})$ for $15 \mathrm{~min}$ on ice in binding medium $(1 \mathrm{mg} /$ $\mathrm{ml}$ BSA in RPMI medium). The cells were then rinsed with icecold PBS, incubated in the presence of Texas red-transferrin in prewarmed medium, and chased at $37^{\circ} \mathrm{C}$ for $60 \mathrm{~min}$. The fixed cells were double-stained for pEGFR with anti-pEGFR monoclonal antibody and LIMPII with anti-LIMPII antibody.

Western blot analysis. Protein samples were separated by sodium dodecyl sulfate (SDS)-polyacrylamide gel electrophoresis (PAGE) and then transferred to polyvinylidene difluoride membranes (Millipore, Billerica, MA, USA). Following blocking, the membrane was blotted with the appropriate antibody, and subsequently, horseradish peroxidase-conjugated anti-mouse or anti-rabbit IgG (GE Healthcare Bioscience, Tokyo, Japan) was applied. The final signal was revealed by ECL chemiluminescence (Pierce, Rockford, IL, USA). Digital images were analyzed with NIH Image software to measure the density of each band without a saturated signal.

EGF-stimulated EGFR degradation. PC9 and A549 cells were starved for $12 \mathrm{~h}$ with RPMI without FBS at $37^{\circ} \mathrm{C}$. The serumstarved cells were then preincubated for $30 \mathrm{~min}$ in the presence of CHX $(20 \mu \mathrm{g} / \mathrm{ml})$ before incubation with EGF $(100 \mathrm{ng} / \mathrm{ml})$ at $37^{\circ} \mathrm{C}$ for the indicated times. The cells were then washed with ice-cold-PBS and lysed, followed by SDS-PAGE and western blot analysis. Bafilomycin A1 $(0.17 \mu \mathrm{M})$ was added when the cells were incubated with RPMI.

Statistical analysis. Data are expressed as mean \pm SD unless otherwise noted. Significance $(\mathrm{P}<0.05)$ was determined by using Student's t-test, since all data met the assumptions for parametric statistical analysis.

\section{Results}

Silencing of SNX1 by specific siRNA effectively downregulates the expression of endogenous SNX1 protein levels, and increases expression of EGFR $m R N A$ in the 3 NSCLC cell lines. To investigate the biological function of SNX1 in regulating EGFR endocytosis, we used siRNA to knock down the endog- 


\section{A PC9}
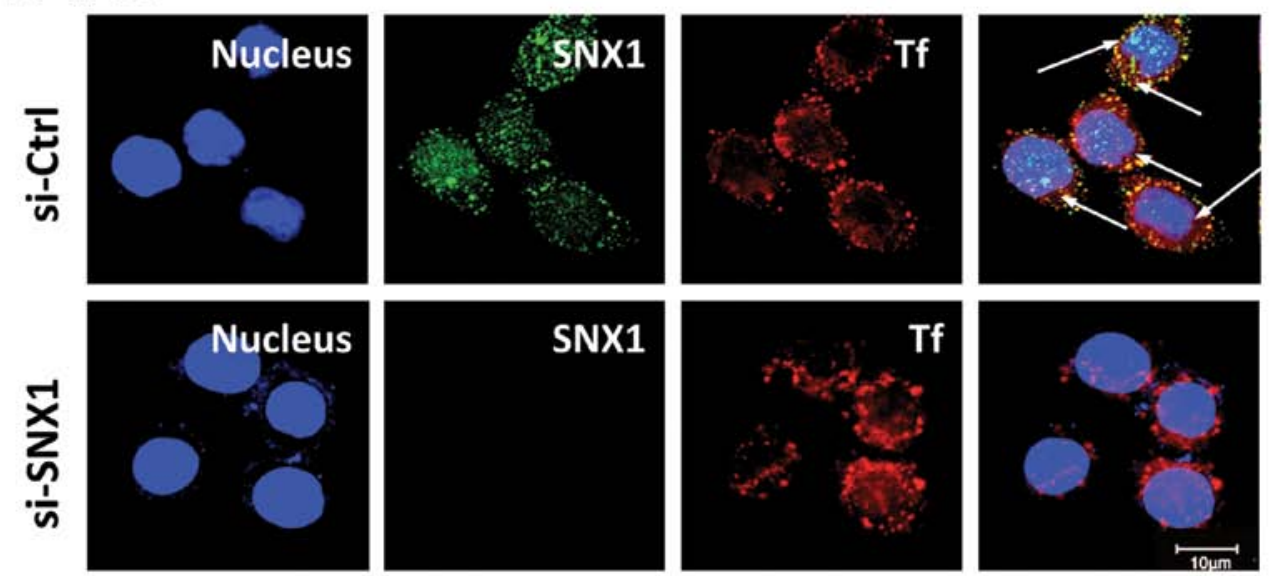

\section{B QG56}
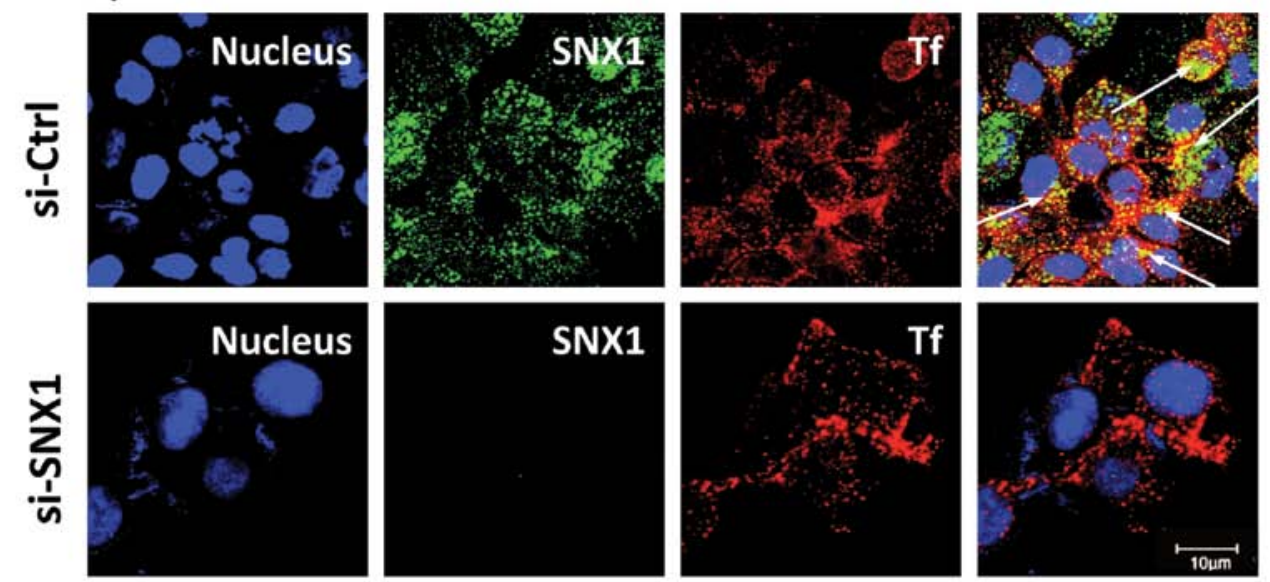

\section{A549}
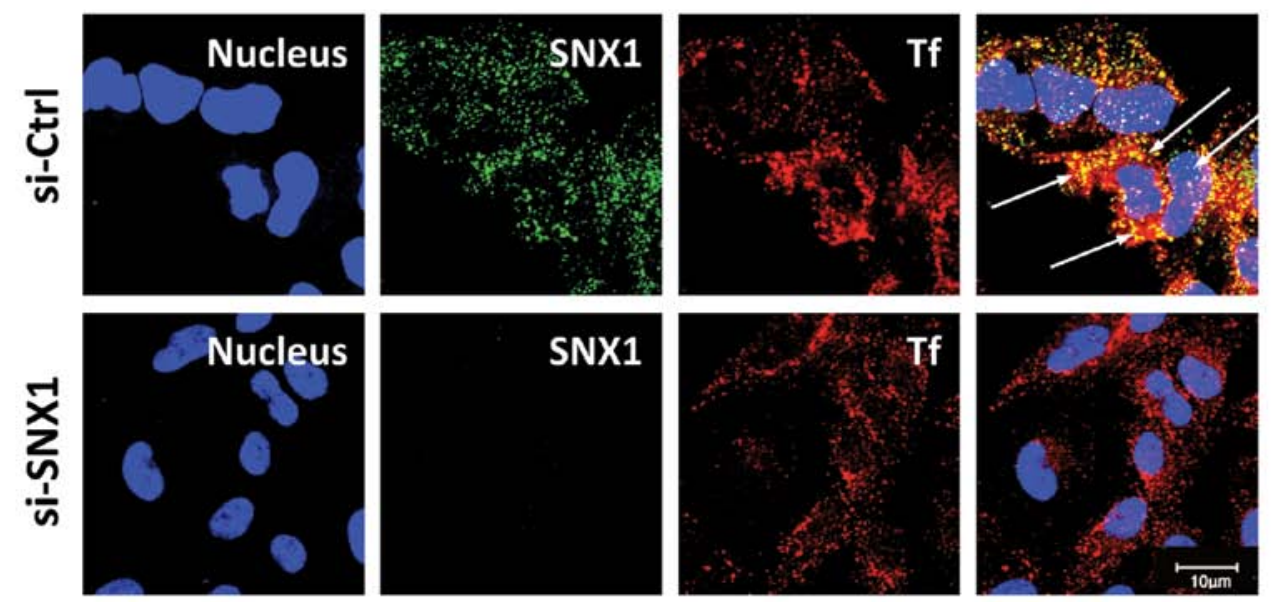

Figure 1. Silencing of SNX1 by sequence specifc siRNA effectively depletes the expression of endogenous SNX1 protein. The 3 NSCLC cell lines PC9 (A), QG56 (B) and A549 (C) cells transfected with siRNA-control (si-Ctrl) or siRNA-SNX1 (si-SNX1) were incubated with Texas red-transferrin (red) and fixed as described in Materials and methods. Then cells were double-stained for SNX1 (green) and Tf (red). The merged confocal images as yellow color are indicated by white arrows. Each cell line was stained with DAPI (blue) to reveal the nuclei. In the 3 NSCLC cell lines transfected with si-Ctrl, SNX1 was predominantly colocalized with the endocytosed Texas red-transferrin-positive early endosomes. However, SNX1-positive staining was not seen in the siRNA-SNX1-transfected cells, thereby indicating that SNX1 protein expression is considerably suppressed by specific siRNA-SNX1. Bar, $10 \mu \mathrm{m}$.

enous of SNX1 in 3 NSCLC cell lines, namely, PC9, QG56 and A549. Firstly, we examined the depletion of endogenous SNX1 protein levels by confocal immunofluorescence microscopy. As shown in Fig. 1, the expression of endogenous SNX1 was successfully depleted using siRNA in the 3 NSCLC cell lines. Therefore, we used these cells to analyze the internalization fate of Texas red-EGF or pEGFR over time, as described in Materials and methods. 
A SNX1

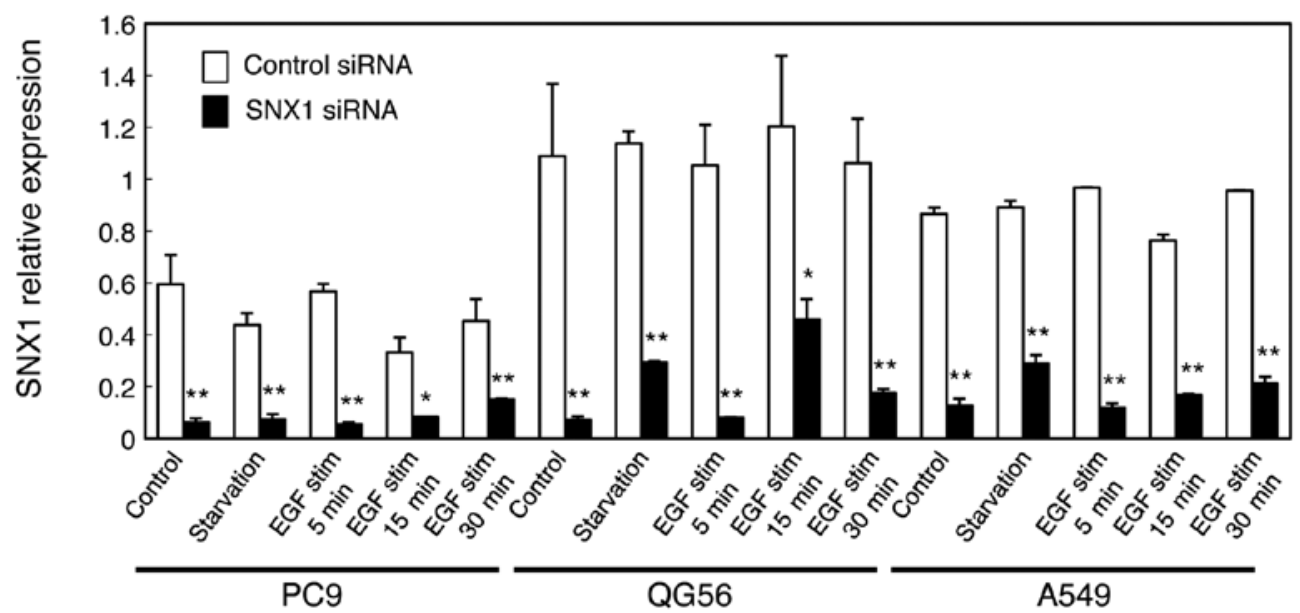

B EGFR

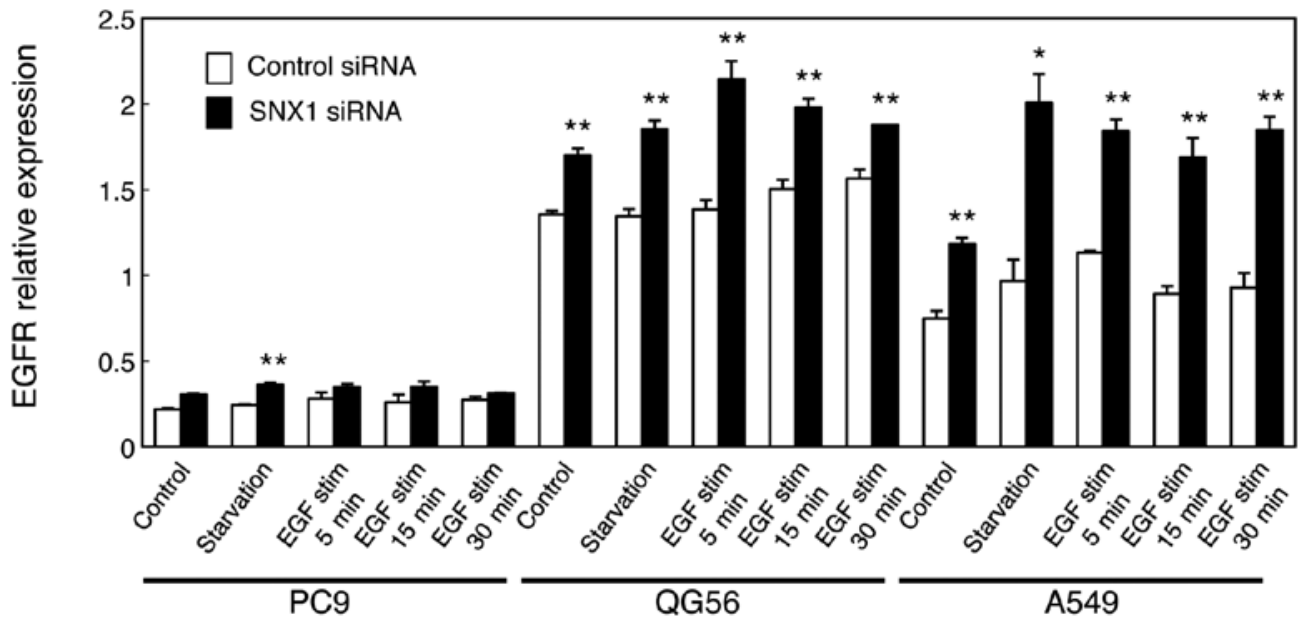

Figure 2. qRT-PCR analysis of SNX1 (A) and EGFR (B) mRNAs in 3 NSCLC cell lines PC9, QG56 and A549 cells transfected with siRNA-control or siRNASNX1. The 3 NSCLC cell lines PC9, QG56 and A549 cells transfected with si-Ctrl or si-SNX1 were stimulated at $37^{\circ} \mathrm{C}$ with EGF (100 ng/ml) for the indicated times, and then analyzed for the expression of SNX1 (A) and EGFR (B) mRNAs by qRT-PCR analysis as described in Materials and methods. Expression levels of SNX1 and EGFR mRNAs were normalized with that of $\beta$-actin. The error bar denotes SD from three separate experiments, and significance was determined using Student's t-test. Asterisk indicates significant difference between the values $\left({ }^{*} \mathrm{P}<0.05 ;{ }^{* *} \mathrm{P}<0.01\right)$.

Next, we treated the 3 NSCLC cell lines with EGF for different time periods, and then used qRT-PCR analysis to examine the endogenous SNX1 mRNA transcript levels. As shown in Fig. 2A, the results revealed that siRNA-SNX1 reduced SNX1 mRNA in all 3 NSCLC cell lines. Moreover, it should be noted that a large amount of SNX1 transcript was observed in the gefitinib-resistant cell lines, QG56 and A549, compared to the gefitinib-sensitive cell line PC9 (Fig. 2A).

In addition, we found that SNX1 knockdown increased endogenous expression of EGFR transcript in the 3 NSCLC cell lines (Fig. 2B). We also found that endogenous expression of EGFR mRNA transcripts was considerably higher in the gefitinib-resistant cell lines QG56 and A549, compared to the gefitinib-sensitive cell line PC9: the expression level of EGFR transcript in the gefitinib-resistant cell lines QG56 and A549 cells was approximately 6.2-fold and 3.4-fold, respectively, of the values in the gefitinib-sensitive PC9 cells (Fig. 2B). These results imply that SNX1 is involved in the negative regulation of EGFR mRNA expression in these human lung cancer cells.

Silencing of SNX1 stimulates an efficient endocytosis of ligandinduced EGFR and phosphorylated EGFR via the early/late endocytic pathway in gefitinib-resistant NSCLC cell lines. We recently demonstrated novel evidence that gefitinib-sensitive cells show efficient endocytosis of EGFR. In contrast, gefitinibresistant cells show internalized EGFR accumulation in the aggregated early endosomes, and this is associated with SNX1 $(13,14)$. We, therefore, suggest that impairment of protein function, such as SNX1 in the regulation of EGFR trafficking in the early endocytic pathway, might cause these perturbations in EGFR endocytosis, leading to gefitinib-resistance in NSCLC cell lines.

To further examine the effect of SNX1 silencing on ligandinduced EGFR via the early/late endocytic pathway, we studied the fate of internalized Texas red-EGF in early endosomes or 


\section{A}
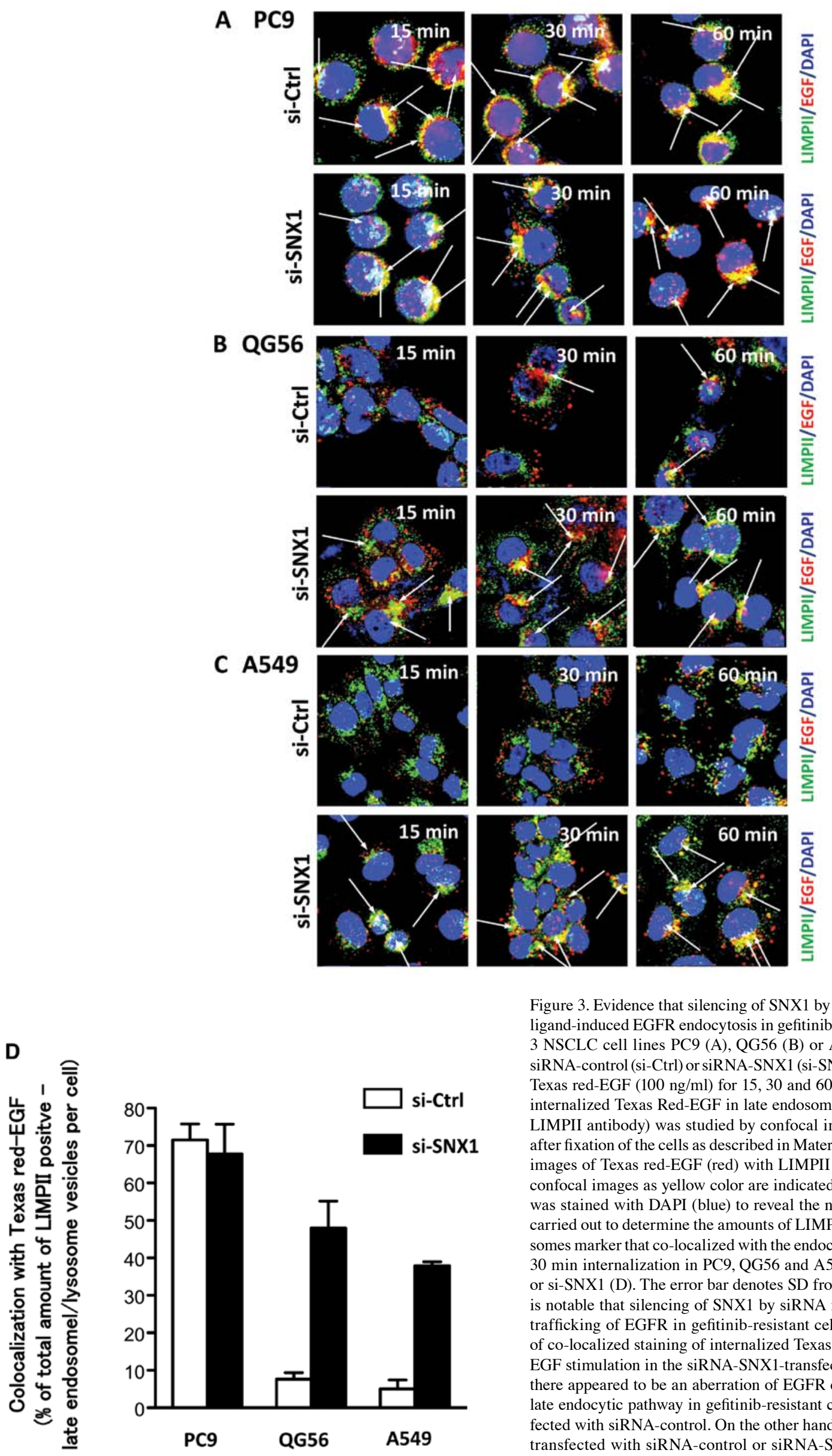

Figure 3. Evidence that silencing of SNX1 by specific siRNA rescues efficient ligand-induced EGFR endocytosis in gefitinib-resistant NSCLC cell lines. The 3 NSCLC cell lines PC9 (A), QG56 (B) or A549 (C) cells transfected with siRNA-control (si-Ctrl) or siRNA-SNX1 (si-SNX1) were incubated at $37^{\circ} \mathrm{C}$ with Texas red-EGF $(100 \mathrm{ng} / \mathrm{ml})$ for 15,30 and $60 \mathrm{~min}$, and the distribution of the internalized Texas Red-EGF in late endosomes/lysosomes (stained with antiLIMPII antibody) was studied by confocal immunofluorescence microscopy after fixation of the cells as described in Materials and methods. Superimposed images of Texas red-EGF (red) with LIMPII (green) are shown. The merged confocal images as yellow color are indicated by white arrows. Each cell line was stained with DAPI (blue) to reveal the nuclei. Quantitative analysis was carried out to determine the amounts of LIMPII-positive late endosomes/lysosomes marker that co-localized with the endocytosed Texas red-EGF following 30 min internalization in PC9, QG56 and A549 cells transfected with si-Ctrl or si-SNX1 (D). The error bar denotes SD from three separate experiments. It is notable that silencing of SNX1 by siRNA rescued a rapid endocytosis and trafficking of EGFR in gefitinib-resistant cells, since the increased amounts of co-localized staining of internalized Texas red-EGF and LIMPII following EGF stimulation in the siRNA-SNX1-transfected cells (B and C). In contrast, there appeared to be an aberration of EGFR endocytosis through the early to late endocytic pathway in gefitinib-resistant cell lines QG56 and A549 transfected with siRNA-control. On the other hand, in gefitinib-sensitive PC9 cells transfected with siRNA-control or siRNA-SNX1, a rapid internalization of Texas red-EGF was observed (A), thereby indicating that depletion of SNX1 does not have any inhibitory effect on the EGFR endocytosis. 
late endosomes/lysosomes in 3 NSCLC cell lines. The gefitinibsensitive PC9 cells or gefitinib-resistant QG56 and A549 cells transfected with siRNA-control or siRNA-SNX1 were incubated with Texas Red-EGF for different time periods and the distribution of internalized Texas red-EGF was then assessed by confocal immunofluorescence microscopy. In gefitinib-sensitive PC9 cells transfected with siRNA-SNX1, a rapid endocytosis of Texas red-EGF was observed, and the distribution of small punctate vesicles that stained positive for internalized EGF overlapped with the LIMPII-positive late endosomes/lysosomes in the perinuclear region (Fig. 3A). Moreover, a considerable amount of the internalized Texas red-EGF co-localized with the LIMPII-positive late endosomes/lysosomes after $30 \mathrm{~min}$. These observations are consistent with those for PC9 cells transfected with siRNA-control, therefore, suggesting that silencing of SNX1 does not have any inhibitory effect on EGFR endocytosis.

On the other hand, in the gefitinib-resistant QG56 and A549 cells transfected with siRNA-control, the internalization of Texas red-EGF was suppressed and the endocytosed Texas red-EGF-positive staining was not co-localized with LIMPIIpositive vesicular structures even after $30 \mathrm{~min}$ internalization (Fig. 3B and C). Therefore, the transfection of siRNA-control did not change the suppressive internalization of the ligandinduced EGFR in the gefitinib-resistant QG56 and A549 cell lines. In contrast, in the gefitinib-resistant QG56 and A549 cells transfected with siRNA-SNX1, we found an increase in the co-localization of Texas red-EGF and LIMPII at 15 and 30 min after EGF stimulation.

Quantitative analysis was carried out to determine the amounts of LIMPII-positive late endosomes/lysosomes marker co-localized with the endocytosed Texas red-EGF after 30-min internalization in PC9, QG56 and A549 cells transfected with siRNA-control or siRNA-SNX1 (Fig. 3D). Our data confirm that silencing of SNX1 by siRNA rescues a rapid endocytosis and trafficking of EGFR via the early/late endocytic pathway in gefitinib-resistant cells. In contrast, an aberration of EGFR endocytosis was noted through the early to late endocytic pathway in the gefitinib-resistant cells transfected with siRNA-control. These results demonstrate that depletion of SNX1 by siRNA considerably stimulates ligandinduced EGFR endocytosis in the gefitinib-resistant QG56 and A549 cells.

To further substantiate the effect of SNX1 silencing on the ligand-induced phosphorylation of EGFR and the endocytosis of pEGFR, the 3 NSCLC cell lines transfected with siRNAcontrol or siRNA-SNX1 were stimulated with EGF for $60 \mathrm{~min}$, and then each cell type was double-stained for pEGFR and the endocytosed transferrin or for pEGFR and LIMPII. In the gefitinib-resistant cell lines QG56 and A549 transfected with siRNA-control, pEGFR remained predominantly associated with the transferrin-positive early endosomes, but no colocalization of pEGFR with LIMPII-positive vesicles was seen in the cells (Fig. 4B and C). In contrast, we found a significant increase in co-localized pEGFR and LIMPII in the cells transfected with siRNA-SNX1 (Fig. 4B and C). These results confirm that silencing of SNX1 stimulates ligand-induced pEGFR endocytosis via the early/late endocytic pathway in a gefitinib-resistant NSCLC cell line. On the other hand, in the gefitinib-sensitive PC9 cells transfected with siRNA-control or siRNA-SNX1, we observed an efficinet pEGFR endocy- tosis from early endosomes to late endosomes. In addition, EGFR co-localized with the LIMPII-positive vesicles as well as the transferrin-positive early endosomes after EGF stimulation (Fig. 4A). These results indicate that depletion of SNX1 by siRNA does not have any inhibitory effect on ligandinduced pEGFR endocytosis in gefitinib-sensitive PC9 cells. Quantitative analysis of LIMPII-positive late endosome/lysosome marker (Fig. 4D) that co-localized with the endocytosed pEGFR after 60 min of internalization further confirmed the stimulating effect of SNX1 silencing on the ligand-induced endocytic trafficking of pEGFR from early endosomes to late endosomes in the gefitinib-resistant NSCLC cells.

Depletion of SNX1 stimulates the ligand-induced degradation of EGFR and increases EGFR phosphorylation in gefitinibresistant NSCLC cell line. To analyze the EGF-stimulated degradation of EGFR or pEGFR in the gefitinib-sensitive cell line PC9, the cells were stimulated with EGF at $37^{\circ} \mathrm{C}$ for the indicated times, and then analyzed by western blotting. The results revealed that the degradation of EGFR proceeded efficiently in the PC9 cells (Fig. 5A), and the amounts of EGFR or pEGFR decreased by about $80 \%$ after $120 \mathrm{~min}$ (Fig. 5B and $\mathrm{C}$ ). Further, we tested if the lysosomal protease inhibitor bafilomycin A1 prevents the EGF-induced accelerated degradation of EGFR and pEGFR in PC9 cells. Cells were pretreated with bafilomycin A1 for $30 \mathrm{~min}$, and then stimulated with EGF for various periods, and the lysates were analyzed by western blotting. The results showed that bafilomycin A1 treatment completely blocked EGF-induced degradation of EGFR and pEGFR, as indicated by the expression of these molecules remaining in the cells following incubation (Fig. 5). However, no inhibitory effect was seen when the cells were treated in the presence of MG132, a proteasomal inhibitor (data not shown). The strong inhibition of bafilomycin A1 on EGF-stimulated EGFR degradation was consistent with previously reported data (29).

Quantitative analysis showed that EGFR and pEGFR were degraded by more than $70 \%$ within $1 \mathrm{~h}$ of EGF stimulation, and they gradually disappeared from the cells in the $120 \mathrm{~min}$ following stimulation (Fig. 5B and C); however, in the cells treated with bafilomycin A1, more than $94 \%$ of the EGFR or pEGFR remained in the cells after 120 min of EGF stimulation. Therefore, these results indicate that intracellular degradation of EGFR or pEGFR proceeds efficiently via an endosomal/ lysosomal pathway in PC9 cells.

Next, to further examine the effect of the silencing of SNX1 protein levels on the EGF-induced degradation of EGFR or pEGFR in the gefitinib-resistant A549 cells, the cells transfected with siRNA-control or siRNA-SNX1 were stimulated with $\mathrm{EGF}$ at $37^{\circ} \mathrm{C}$ for the indicated times, and then, the cell lysates were analyzed by western blotting. As shown in Fig. 6A and B, we found an accelerated EGF-dependent degradation of EGFR in the siRNA-SNX1-transfected A549 cells, with degradation of approximately $72 \%$ at $60 \mathrm{~min}$ and $85 \%$ at $120 \mathrm{~min}$ after EGF stimulation. In contrast, the EGFR degradation was about $45 \%$ at $60 \mathrm{~min}$ and $65 \%$ at $120 \mathrm{~min}$ after EGF stimulation in the siRNA-control-transfected cells. These results indicate that the depletion of SNX1 by siRNA stimulates the EGF-dependent EGFR downregulation via the early/late endocytic pathway in the gefitinib-resistant cell line. 


\section{A PC9}
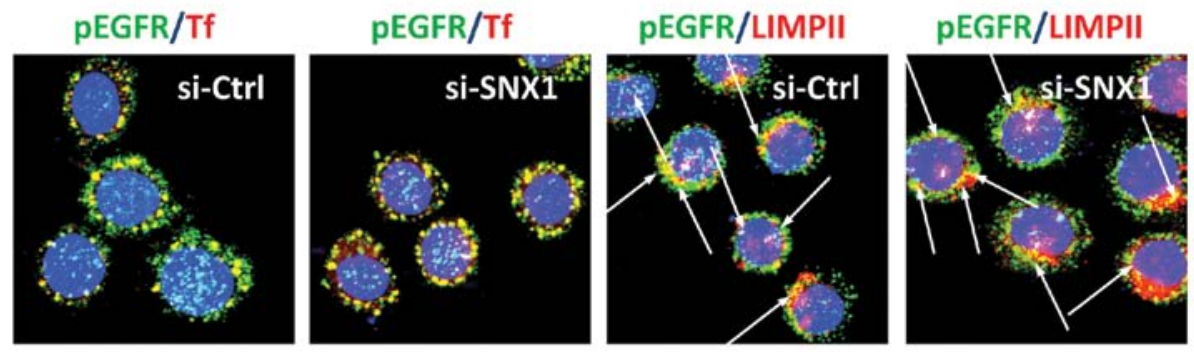

\section{B QG56}
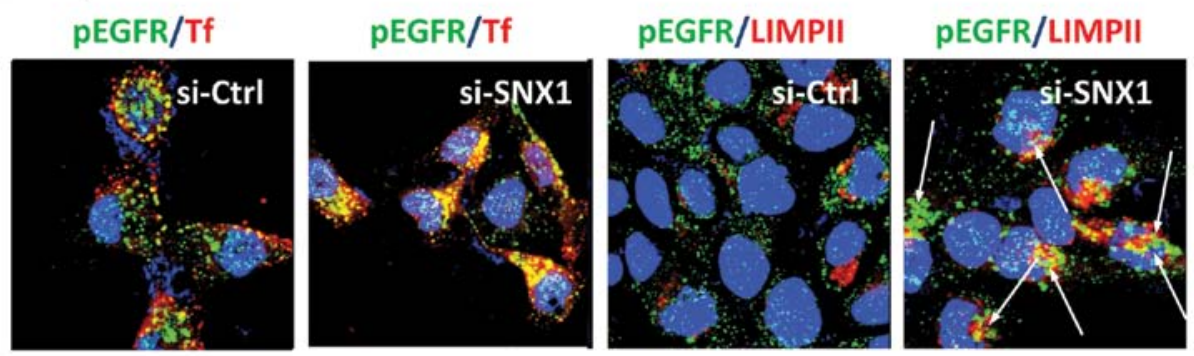

\section{C $\mathbf{A 5 4 9}$}
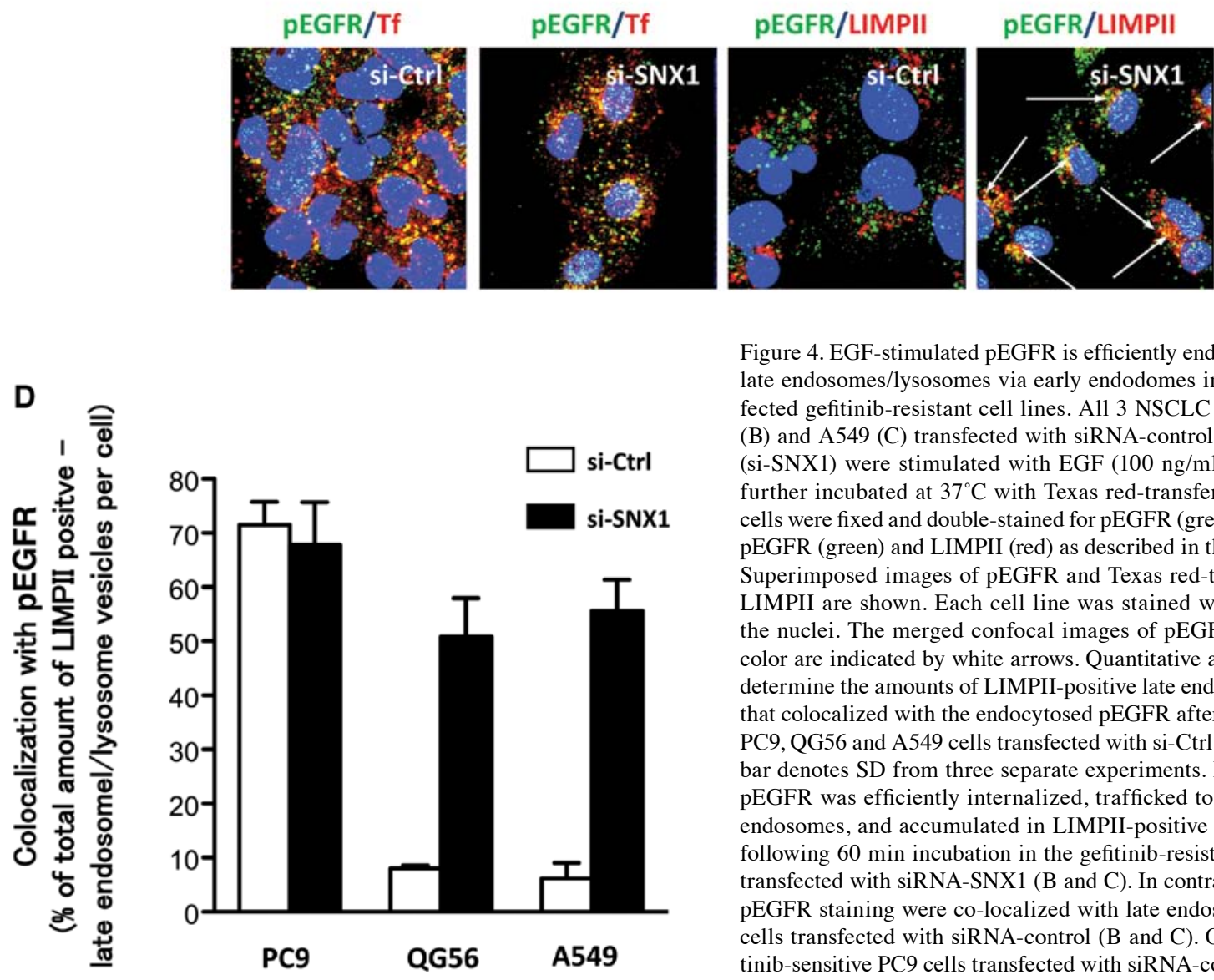

Figure 4. EGF-stimulated pEGFR is efficiently endocytosed and trafficked to late endosomes/lysosomes via early endodomes in the siRNA-SNX1-transfected gefitinib-resistant cell lines. All 3 NSCLC cell lines PC9 (A), QG56 (B) and A549 (C) transfected with siRNA-control (si-Ctrl) or siRNA-SNX1 (si-SNX1) were stimulated with EGF $(100 \mathrm{ng} / \mathrm{ml})$ for $15 \mathrm{~min}$ on ice were further incubated at $37^{\circ} \mathrm{C}$ with Texas red-transferrin (red) for $60 \mathrm{~min}$, and cells were fixed and double-stained for pEGFR (green) and transferrin (red) or pEGFR (green) and LIMPII (red) as described in the Materials and methods. Superimposed images of pEGFR and Texas red-transferrin or pEGFR and LIMPII are shown. Each cell line was stained with DAPI (blue) to reveal the nuclei. The merged confocal images of pEGFR and LIMPII as yellow color are indicated by white arrows. Quantitative analysis was carried out to determine the amounts of LIMPII-positive late endosomes/lysosomes marker that colocalized with the endocytosed pEGFR after $60 \mathrm{~min}$ internalization in PC9, QG56 and A549 cells transfected with si-Ctrl or si-SNX1 (D). The error bar denotes SD from three separate experiments. Note that EGF-stimulated pEGFR was efficiently internalized, trafficked to late endosomes via early endosomes, and accumulated in LIMPII-positive late endosomeslysosomes following $60 \mathrm{~min}$ incubation in the gefitinib-resistant QG56 and A549 cells transfected with siRNA-SNX1 (B and C). In contrast, only small amounts of pEGFR staining were co-localized with late endosomes in QG56 and A549 cells transfected with siRNA-control (B and C). On the other hand, in gefitinib-sensitive PC9 cells transfected with siRNA-control or siRNA-SNX1, an efficient internalization of EGFR was seen (A), suggesting that SNX1 might be involved in the negative regulation of pEGFR endocytosis in NSCLC cells.

Furthermore, we found novel evidence that the expression level of pEGFR was dramatically increased at 60 and $120 \mathrm{~min}$ after EGF stimulation in the siRNA-SNX1-transfected A549 cells compared to the increase seen in siRNA-control-transfected

A549 cells (Fig. 6A and C), and that the induced expression level of pEGFR protein following EGF stimulation was about 33-fold and 9.4-fold at 60 and 120 min, respectively (Fig. 6A and C). In contrast, in the siRNA-control-transfected A549 cells, the 


\section{A}

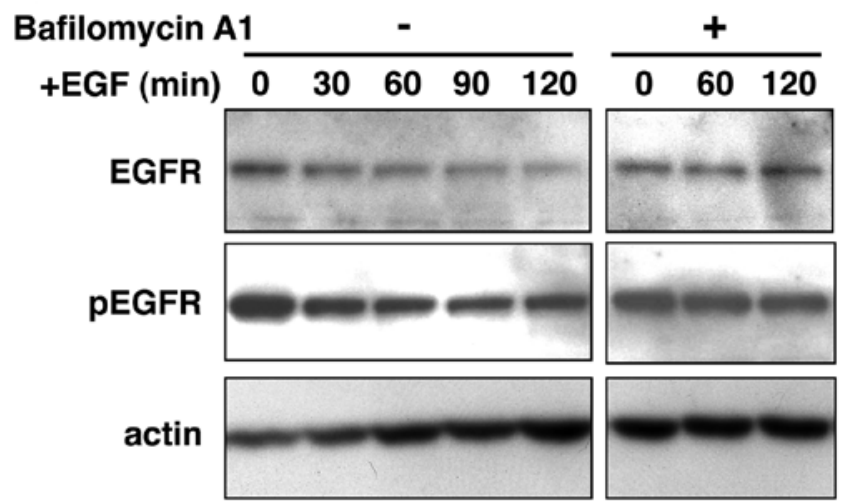

B

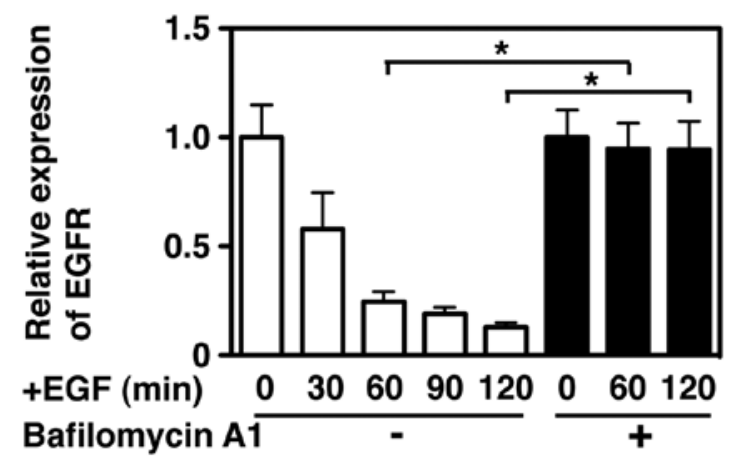

C

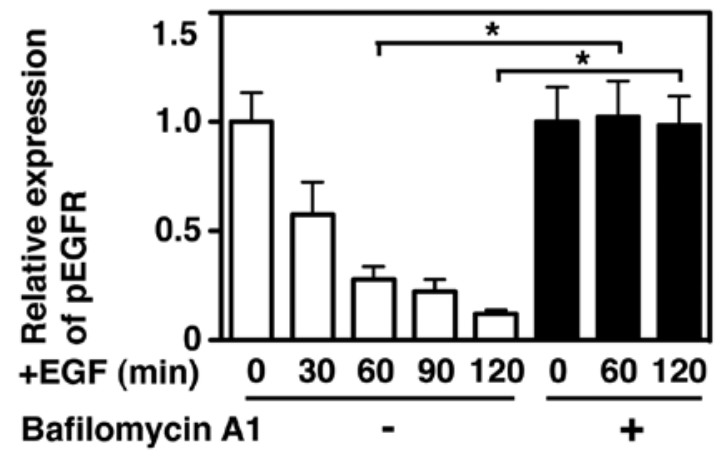

Figure 5. An efficient ligand-induced degradation of EGFR and pEGFR are suppressed by bafilomycin A1 in gefitinib-sensitive cell line. PC9 cells were starved for $12 \mathrm{~h}$, followed by pretreatment with or without bafilomycin A1 for $30 \mathrm{~min}$ in the presence of CHX $(20 \mu \mathrm{g} / \mathrm{ml})$, and stimulated with EGF $(100 \mathrm{ng} / \mathrm{ml})$ at $37^{\circ} \mathrm{C}$ for the times indicated. Cells were lysed, followed by SDS-PAGE and western blot analysis (A) as described in Materials and methods. The amounts of EGFR or pEGFR remaining in the cell lysates following EGF stimulation was quantified using NIH Image software, and was plotted after normalization with $\beta$-actin (B and C). The error bar denotes SD from three separate experiments, and significance was determined using Student's t-test. Asterisk indicates significant difference between the values $\left({ }^{*} \mathrm{P}<0.05\right)$.

increase of the pEGFR expression was only 7.5 -fold and 4.3 -fold at 60 and 120 min, respectively (Fig. 6A and C). The increased pEGFR appeared to be rapidly degraded within $120 \mathrm{~min}$ in both the siRNA-control- and siRNA-SNX1-transfected cells (Fig. 6C and D), indicating that pEGFR is efficiently trafficked to the lysosomal degradation pathway. It should be noted that the expression levels of pEGFR in the siRNA-SNX1-transfected cells was 13.8-fold (at $60 \mathrm{~min}$ ) and 6.7-fold (at $120 \mathrm{~min}$ ) higher than that in the siRNA-control-transfected cells after EGF stimulation (Fig. 6E). These results indicate that depletion of SNX1 by siRNA efficiently increases endogenous phosphorylation of EGFR via the endocytic pathway, implying that SNX1 plays a suppressive role in the phosphorylation and downregulation of EGFR via endocytic pathway in human lung cancer cells.

\section{Discussion}

In the present study, we demonstrate for the first time the intracellular regulatory function of SNX1 with regard to EGF-induced endocytosis and downregulation of EGFR/ pEGFR using RNAi-mediated knockdown approaches via the early/late endocytic pathway in gefitinib-sensitive and gefitinib-resistant NSCLC cell lines. Using confocal immunofluorescence microscopy and qRT-PCR, we verified a considerable reduction of endogenous SNX1 protein expression and mRNA expression, respectively, in all 3 NSCLC cell lines transfected with siRNA-SNX1. Moreover, we found that endogenous expression of EGFR transcripts in the gefitinib-resistant cell lines QG56 and A549 was significantly higher than in the gefitinib-sensitive cell line PC9, and knockdown of SNX1 in all 3 NSCLC cell lines considerably increased the expression of the EGFR transcript. From these findings, we propose that the expression of SNX1 protein might play a negative role in the regulation of EGFR mRNA expression in these NSCLC cell lines.

Most importantly, we provided evidence by using confocal immunofluorescence microscopy that knockdown of endogenous SNX1 by siRNA-SNX1 induced efficient endocytosis of ligand-induced EGFR or pEGFR via the early/late endocytic pathway in the gefitinib-resistant NSCLC cell lines QG56 and A549. We showed that increased co-localization of Texas red-EGF and LIMPII after 15 min internalization, while in the siRNA-control-tranfected gefitinib-resistant cells, the internalization of EGFR was suppressed and the endocytosed Texas red-EGF-positive staining did not overlap with late endosomepositive vesicular structures even after $30 \mathrm{~min}$ stimulation. These data suggest that knockdown of SNX1 stimulates ligandinduced EGFR endocytosis in the gefitinib-resistant cells.

Inhibition of EGFR/pEGFR degradation in PC9 cells was verified using bafilomycin A1, a lysosomal inhibitor. We found that bafilomycin A1 treatment in PC9 cells completely blocked the efficient EGF-induced degradation of EGFR/ pEGFR, confirming that the EGF-induced EGFR or pEGFR is trafficked to late endosomes/lysosomes where extensive degradation for these proteins takes place in the PC9 cells. We further showed, by using western blot analysis, that depletion of SNX1 considerably stimulates the ligand-induced downregulation of EGFR in the gefitinib-resistant A549 cells. This result indicates that silencing of SNX1 stimulates EGFR traffic out of early endosomes for targeting lysosomal degradation pathway. Accordingly, we postulate that SNX1 might be a negative regulator of ligand-induced EGFR endocytosis, followed by downregulation via the early/late endocytic pathway.

It was also interesting to note that silencing of SNX1 induced a dramatic increase in the expression of pEGFR in the siRNA-SNX1-transfected A549 cells. Further, the observed increase of pEGFR at $60 \mathrm{~min}$ in the siRNA-SNX1-transfected cells was approximately 14 -fold higher than that in the siRNAcontrol-transfected cells. This marked increase in pEGFR expression was not seen in the siRNA-control-transfected cells. 
A Con-siRnA SNX1-siRNA

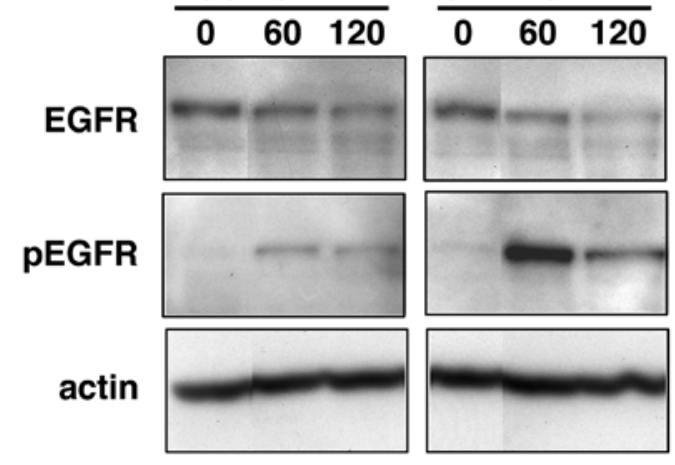

B

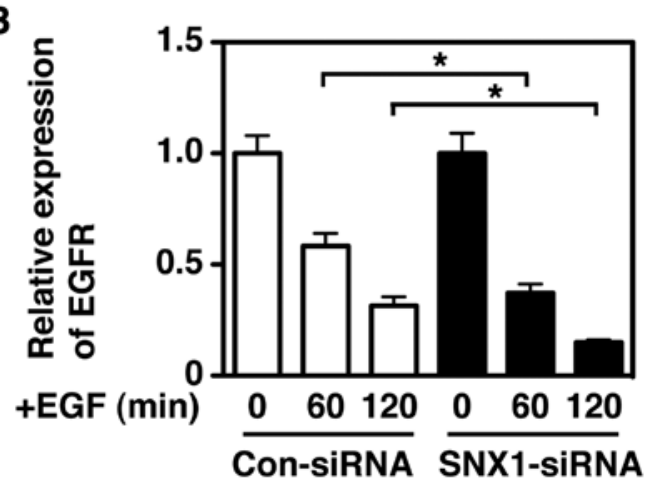

C
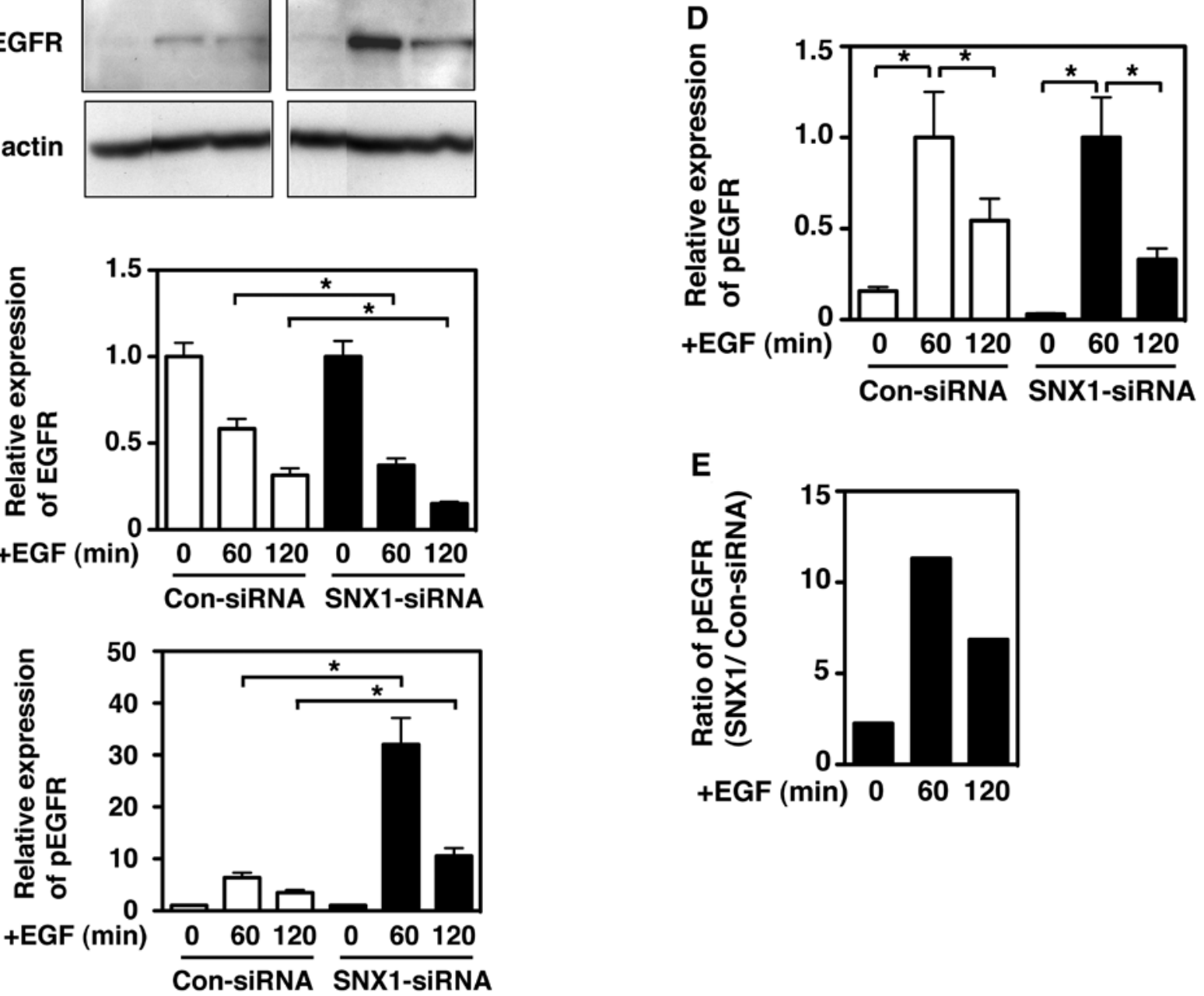

E

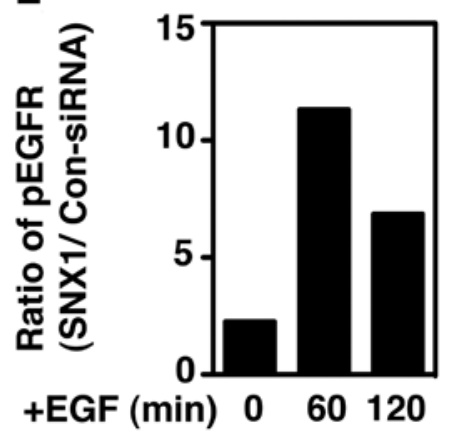

Figure 6. Depletion of SNX1 stimulates ligand-induced degradation of EGFR and increases EGFR phosphorylation in gefitinib-resistant NSCLC cell line. The A549 cells transfected with siRNA-control (si-Ctrl) or siRNA-SNX1 (si-SNX1) were starved for $12 \mathrm{~h}$, followed by incubation with CHX (20 $\mu \mathrm{g} / \mathrm{ml})$ and EGF $(100 \mathrm{ng} / \mathrm{ml})$ at $37^{\circ} \mathrm{C}$ for the times indicated. Cells were lysed, followed by SDS-PAGE and western blot analysis (A) as described in Materials and methods. The amounts of EGFR (B) or pEGFR (C) remaining in the cell lysates following EGF stimulation were quantified using NIH Image software, and were plotted after normalization with $\beta$-actin (B and C). Relative expression of pEGFR in the siRNA-control-transfected cells or siRNA-SNX1-transfected cells is shown in (D). Ratio of pEGFR expression at the time indicated following EGF stimulation in the siRNA-SNX1-transfected-cells relative to that in the siRNA-control-transfected cells is shown in (E). The error bar denotes SD from three separate experiments, and significance was determined using Student's t-test. Asterisk indicates significant difference between the values ( $\mathrm{P}<0.05$ ). Note that an accelerated EGF-dependent degradation of EGFR was observed in the siRNA-SNX1 transfected A549 cells, as compared to the siRNA-control-transfected cells (A and B), thereby suggesting that SNX1 could play a suppressive role in the EGFR downregulation via endocytic pathway in NSCLC cells. Also, an induced expression of pEGFR was seen at 60 min and 120 min following EGF stimulation in the siRNA-SNX1transfected A549 cells, and the increased pEGFR expression was about 33-fold and 9.4-fold at 60 min and 120 min, respectively (C and E).

These results indicate that depletion of SNX1 protein by siRNA considerably increases endogenous phosphorylation of EGFR via the endocytic pathway. It is known that following EGF stimulation, the phosphorylated EGFR is internalized by rapid clathrin-mediated endocytosis, and the internalized EGFR is then sorted via the endosomal-sorting complex required for transport (ESCRT)-dependent pathway for targeting degradation or recycling pathway (30). In this context, our present results, demonstrating the suppressive role of $\mathrm{SNX1}$ on the phosphorylation of EGFR via the endocytic pathway, suggest a critical function for SNX1 in the maintenance of tightly regulated EGFR-mediated signaling.

We recently reported the novel observation that in the gefitinib-resistant NSCLC cell line, early endosomes labeled with endocytosed Texas red-transferrin formed aggregated vesicular structures distributed in the perinuclear region, and that considerable amounts of cytosolic SNX1 were distributed in these aggregated early endosomal vesicles $(13,14)$. Conversely, 
no such aggregation of SNX1-positive early endosomes was observed in the gefitinib-sensitive NSCLC cell line. On the basis of these data, we postulated that membrane trafficking of pEGFR from early endosomes to late endosomes might be significantly impaired in the gefitinib-resistant NSCLC A549 and QG56 cells. Therefore, we assume that abrogation of certain SNX1 trafficking machinery could cause this perturbation of EGFR endocytosis, which might lead to the acquisition of gefitinib-resistance in NSCLC cell lines.

It was originally reported that SNX1 interacts with EGFR, and the overexpression of SNX1 enhanced EGF-dependent EGFR degradation in lysosomes, thereby demonstrating that SNX1 is a likely mediator in the intracellular sorting of EGFR for targeting the lysosomes for degradation (15). In this context, our findings regarding the suppressive role of SNX1 appear to be in contrast to previous findings $(15,20)$. Further studies to investigate the role of SNX1 on EGFR activation and signaling in NSCLC cell lines will be required.

\section{Acknowledgements}

This work was supported by JSPS KAKENHI Grant numbers 23390372, 23659734 and 23592202.

\section{References}

1. Ullrich A and Schlessinger J: Signal transduction by receptors with tyrosine kinase activity. Cell 61: 203-212, 1990.

2. Carpenter G: The EGF receptor: a nexus for trafficking and signaling. Bioessays 22: 697-707, 2000.

3. Yarden Y: The EGFR family and its ligands in human cancer signaling mechanisms and therapeutic opportunities. Eur J Cancer 37: 3-8, 2001.

4. Schlessinger J: Common and distinct elements in cellular signaling via EGF and FGF receptors. Science 306: 1506-1507, 2004

5. Mendelsohn J and Baserga J: The EGF receptor family as targets for cancer therapy. Oncogene 19: 6550-6565, 2000.

6. De Bono JS and Rowinsky EK: The ErbB receptor family: a therapeutic target for cancer. Trends Mol Med 8: 19-26, 2002.

7. Woodburn JR: The epidermal growth factor receptor and its inhibition in cancer therapy. Pharmacol Ther 82: 241-250, 1999.

8. Baselga $\mathbf{J}$ and Averbuch SD: ZD1839 ('Iressa') as an anticancer agent. Drugs 60 (Suppl 1): S33-S42, 2000.

9. Arteaga CL and Johnson DH: Tyrosine kinase inhibitors-ZD1839 (Iressa). Curr Opin Oncol 13: 491-498, 2001.

10. Barker AJ, Gibson KH, Grundy W, Godfrey AA, Barlow JJ, Healy MP, Woodburn JR, Ashton SE, Curry BJ, Scarlett L, Henthorn L and Richards L: Studies leading to the identification of ZD1839 (IRESSA): an orally active, selective epidermal growth factor receptor tyrosine kinase inhibitor targeted to the treatment of cancer. Bioorg Med Chem Lett 11: 1911-1914, 2001.

11. Ono M, Hirata A, Kometani T, Miyagawa M, Ueda S, Kinoshita H, Fujii T and Kuwano M: Sensitivity to gefitinib (Iressa, ZD1839) in non-small cell lung cancer cell lines correlates with dependence on the EGF receptor/extracellular signal-regulated kinase 1/2 and EGF receptor/Akt pathway for proliferation. Mol Cancer Ther 3: 465-472, 2004

12. Nishimura Y, Bereczky B and Ono M: The EGFR inhibitor gefitinib suppresses ligand-stimulated endocytosis of EGFR via the early/late endocytic pathway in non-small cell lung cancer cell lines. Histochem Cell Biol 127: 541-553, 2007.

13. Nishimura Y, Yoshioka K, Bereczky B and Itoh K: Evidence for efficient phosphorylation of EGFR and rapid endocytosis of phosphorylated EGFR via the early/late endocytic pathway in a gefitinib-sensitive non-small cell lung cancer cell line. Mol Cancer 7: 1-13, 2008.
14. Nishimura Y, Yoshioka K, Takiguchi S, Bereczky B, Nakabeppu Y and Itoh K: A role for SNX1 in the regulation of EGF-dependent phosphorylated EGFR endocytosis via the early/late endocytic pathway in a gefitinib-sensitive human lung cancer cells. Curr Signal Transduct Ther 6: 383-395, 2011.

15. Kurten RC, Cadena DL and Gill GN: Enhanced degradation of EGF receptors by a sorting nexin, SNX1. Science 272: 1008-1010, 1996.

16. Worby CA and Dixon JE: Sorting out the cellular function of sorting nexins. Nat Rev Mol Cell Biol 3: 919-931, 2002.

17. Horazdovsky BF, Davies BA, Seaman MN, McLaughlin SA, Yoon S and Emr SD: A sorting nexin-1 homologue, Vps5p, forms a complex with Vps17p and is required for recycling the vacuolar protein-sorting receptor. Mol Biol Cell 8: 1529-1541, 1997.

18. Nothwehr SF and Hindes AE: The yeast VPS5/GRD2 gene encodes a sorting nexin-1-like protein required for localizing membrane proteins to the late Golgi. J Cell Sci 110: 1063-1072, 1997.

19. Seaman MN, McCaffery JM and Emr SD: A membrane coat complex essential for endosome-to-Golgi retrograde transport in yeast. J Cell Biol 142: 665-681, 1998.

20. Zhong Q, Lasar CS, Tronchere H, Sato T, Meerloo T, Yeo M, Songyang Z, Emr SD and Gill GN: Endosomal localization and function of sorting nexin 1. Proc Natl Acad Sci USA 99: 6767-6772, 2002.

21. Carlton J, Bujny M, Peter BJ, Oorschot VM, Rutherford A, Mellor H, Klumperman J, McMahon HT and Cullen PJ: Sorting nexin-1 mediates tubular endosome-to-TGN transport through coincidence sensing of high-curvature membranes and 3-phosphoinositides. Curr Biol 14: 1791-1800, 2004.

22. Gullapalli A, Garrett TA, Paing MM, Griffin CT, Yang Y and Trejo J: A role for sorting nexin 2 in epidermal growth factor receptor down-regulation: evidence for distinct functions of sorting nexin 1 and 2 in protein trafficking. Mol Biol Cell 15: 2143-2155, 2004

23. Okazaki I, Himeno M, Ezaki J, Ishikawa T and Kato K: Purification and characterization of an $85 \mathrm{kDa}$ sialoglycoprotein in rat liver. J Biochem 111: 763-769, 1992.

24. Nishimura Y, Yoshioka K, Bernard O, Himeno M and Itoh K: LIM kinase 1: evidence for a role in the regulation of intracellular vesicle trafficking of lysosomes and endosomes in human breast cancer cells. Eur J Cell Biol 34: 189-213, 2004.

25. Nishimura Y, Yoshioka K, Bernard O, Bereczky B and Itoh K: A role of LIM kinase 1/cofilin pathway in regulating endocytic trafficking of EGF receptor in human breast cancer cells. Histochem Cell Biol 126: 627-638, 2006.

26. Nishimura Y, Bereczky B, Yoshioka K, Taniguchi S and Itoh K: A novel role of Rho-kinase in the regulation of ligand-induced phosphorylated EGFR endocytosis via the early/late endocytic pathway in human fibrosarcoma cells. J Mol Histol 42: 427-442, 2011.

27. Kornfeld S and Mellman I: The biogenesis of lysosomes. Ann Rev Cell Biol 5: 483-525, 1989.

28. Sandoval IV, Arredondo JJ, Alcalde J, Gonzalez-Noriega A, Vandekerckhove J, Jimenez MA and Rico M: The residues Leu (Ile) 475-Ile (Leu) 476, contained in the extended carboxyl cytoplasmic tail, are critical for targeting of the resident lysosomal membrane protein LIMPII to lysosomes. J Biol Chem 269: 6622-6631, 1994.

29. Skarpen E, Johannessen LE, Bjerk K, Fasteng H, Guren TK, Lindeman B, Thoresen GH, Christoffersen T, Stang E, Huitfeldt HS and Madshus IH: Endocytosed epidermal growth Factor (EGF) receptors contribute to the EGF-mediated growth arrest in A431 cells by inducing a sustained increase in p21/CIP1. Exp Cell Res 243: 161-172, 1998 .

30. Sorkin A and von Zastrow M: Endocytosis and signalling: intertwining molecular networks. Nat Rev Mol Cell Biol 10: 609-622, 2009. 